\title{
The interaction and photostability of some xanthenes and selected azo sensitizing dyes with $\mathrm{TiO}_{2}$ nanoparticles
}

\author{
D. EL Mekkawi and M. S. A. Abdel-Mottaleb ${ }^{\dagger}$ \\ Photoenergy Center and Department of Chemistry, Faculty of Science, Ain Shams University, 11566 Abbassia, Cairo, Egypt
}

\begin{abstract}
We have tested simple Graetzel-type solar cells using semiconductor thin films consisting of $\mathrm{TiO}_{2}$ nanoparticles and some electron injecting dyes. The possibility of using xanthenes (rhodamine 101, fluorescein and 5(6)-carboxyfluorescein) and selected azo dyes (alizarin yellow R, alizarin yellow 2G and carboxyaesenazo) as sensitizers has been explored. Fluorescence and electronic absorption measurements revealed complex formation between the chosen dyes and the surface of the colloidal $\mathrm{TiO}_{2}$. The apparent association constants $\left(\mathrm{K}_{\mathrm{app}}\right)$ of the surface complexes have been estimated and are correlated with the dyeinduced negative shifts of the reduction potential of colloidal $\mathrm{TiO}_{2}$ nanoparticles. Moreover, due to its utmost importance, photostability of the organic dyes in absence and presence of colloidal $\mathrm{TiO}_{2}$ nanoparticles and the influence of the used electrolyte have been examined. The results point to a remarkable enhancement of photostability in the presence of the electrolyte $\left(\mathrm{I}_{3}{ }^{-} / \mathrm{I}^{-}\right)$, which is attributed to fast regeneration of the neutral dye via the redox couple of the electrolyte. Furthermore, photocurrent action spectrum of the fabricated and tested DSC shows the origin of photoelectric output to be optical absorption of the dye used.
\end{abstract}

\section{INTRODUCTION}

Conventional solar cells convert light into electricity by exploiting the photovoltaic effect that exists at semiconductor junctions. They are thus closely related to the transistors and integrated circuits. The semiconductor performs two processes simultaneously: absorption of light and the separation of the electric charges ("electrons" and "holes"), which are formed as a consequence of this absorption. However, to avoid the premature recombination, the semiconductors employed must be highly pure and defect-free. The fabrication of this type of cell presents numerous difficulties, preventing the use of such devices for electricity production on the industrial scale. In contrast the solar cells of our interest work on a different principle, whereby the processes of light absorption and charge separation are differentiated [1]. DSC receives strong interest due to their low fabrication cost, light weight, and flexible structure. Recently, it has been exploited profitably in electronic devices and photoelectrochromic windows.

Here we report on the sensitization of semiconductor particles $\left(\mathrm{TiO}_{2}\right)$ by organic dyes such as xanthenes (rhodamine 101, fluorescein and 5(6)carboxyfluorescein) and azo dyes (alizarin yellow R, alizarin yellow $2 \mathrm{G}$ and carboxyarsenazo). Photostability of these dyes will be determined for possible use as sensitizers for the nanocrystalline solar cell. The role played by redox couple (e.g. $\mathrm{I}_{3}^{-} / \mathrm{I}^{-}$) electrolyte in regenerating the neutral sensitizer dye molecules, and thus, stabilization of the dye molecule will be also

\footnotetext{
†E-mail: solar06@photoenergy.org
}

studied. The chosen dyes possessing carboxylate or hydroxyl function groups that enable direct interaction with the surface of $\mathrm{TiO}_{2}$ particles, thereby providing a path for electron transfer from the excited dye adsorbate to the semiconductor [2, 14-16].

\section{MATERIALS AND METHODS}

2.1. Chemicals and solvents. Rhodamine 101 (A), 5(6)-Carboxyfluorescein (B), Fluorescein (C), Alizarin Yellow R (D), Alizarin Yellow 2G (E), and Carboxyarsenazo III (F) are obtained from Fluka (pure grade) and are used as received. The $\mathrm{TiO}_{2}$ fine powder (Degussa P25) from (Degussa-Hüls Company) and is used without further treatment. Titanium (IV) isopropoxide is obtained from Aldrich (pure grade) and is used for the preparation of $\mathrm{TiO}_{2}$ of colloidal dimension as mentioned in literature [5]. Methanol absolute (Riedel) for HPLC measurement. Stannous chloride AR is obtained from S. D. FIN-CHEM LTD., England and is used as received. Antimony trioxide is obtained from B. D. H., England and was used as received in the preparation of surface conducting glasses. Ethylene glycol is obtained from B. D. H., England. Iodine is obtained from Merck and is used as received. Potassium iodide is obtained from Fluka.

2.2. $p H$ and $U V$-Vis instrumentation. The $\mathrm{pH}$ of the solutions has been adjusted using traces of $\mathrm{HClO}_{4}$ and $\mathrm{NaOH}$ solution. The $\mathrm{pH}$ values were recorded by using JENWAY 3040 Ion Analyser and all pH measurements are recorded at constant temperature at $22^{\circ} \mathrm{C}$. The concentration of dyes was $4 \times 10^{-6} \mathrm{M}$, while the concentration of rhodamine 101 was $1.6 \times 10^{-6} \mathrm{M}$ due 
to its high molar absorbitivity. The absorption spectra have been recorded using He $\lambda$ ios $\alpha$ Unicam spectrophotometer. Fluorescence measurements have been performed using RF-5301 PC SHIMADZU spectrofluorophotometer.

pka values of the dyes are determined spectrophotometrically using eq. (1) where the change of the $\mathrm{pH}$ causes considerable changes in their spectra [17]:

$$
\mathrm{pK}_{\mathrm{a}}=\mathrm{pH}-\log \left(\left(\mathrm{A}-\mathrm{A}_{\mathrm{P}}\right) /\left(\mathrm{A}_{\mathrm{D}}-\mathrm{A}\right)\right)
$$

where $\mathrm{A}$ is the absorbance at a given $\mathrm{pH}, \mathrm{A}_{\mathrm{D}}$ and $A_{P}$ are the observed optical densities (absorbance values) of the fully deprotonated and protonated forms, respectively.

Association constant in the formation of the surface complexes, $\mathrm{K}_{\mathrm{app}}$, is estimated from the changes in absorbance intensity from a Benesi-Hildebrand-type plot at different $\mathrm{TiO}_{2}$ concentrations $[2,18]$ :

$$
\frac{1}{A_{o b s}-A_{o}}=\frac{1}{A_{c}-A_{o}}+\frac{1}{K_{a p p}\left(A_{c}-A_{o}\right)\left[T i O_{2}\right]}
$$

where $A_{o b s}$ is the absorbance of the dye solution containing different concentrations of colloidal $\mathrm{TiO}_{2}, \mathrm{~A}_{\mathrm{o}}$ and $\mathrm{A}_{\mathrm{c}}$ are the absorbances of the dye and the complex $\left\{\mathrm{TiO}_{2}\right.$-dye $\}$, respectively. Therefore, a plot of $1 /\left(\mathrm{A}_{\mathrm{obs}}-\right.$ $\left.A_{o}\right)$ versus $1 /\left[\mathrm{TiO}_{2}\right]$ should yield a linear relationship with a slope equal to $1 /\left(\mathrm{K}_{\mathrm{app}}\left(\mathrm{A}_{\mathrm{c}}-\mathrm{A}_{\mathrm{o}}\right)\right)$ and an intercept equal to $1 /\left(\mathrm{A}_{\mathrm{c}}-\mathrm{A}_{\mathrm{O}}\right)$. From the slope and the intercept, we obtain $\mathrm{K}_{\mathrm{app}}$.

2.3. Photostability. The irradiation source is a $150 \mathrm{~W}$ Xenon arc lamp (PTI-LPS-220 Photon Technology International) operated at $70 \mathrm{~W}$. The light intensity is measured using radiometer (IL 1700 International Light) and is found to be $0.041 \mathrm{~W} / \mathrm{cm}^{2} \cdot \min$. The photochemical reactor is a cylindrical double-walled quartz cell, 50-mm diameter and $50 \mathrm{~mm}$ path length, with inlet and outlet for cooling by water to maintain the temperature constant at $22^{\circ} \mathrm{C} \pm 0.2$. The illumination surface area is $15 \mathrm{~cm}^{2}$. In the irradiation processes $100 \mathrm{ml}$ of the aqueous solutions is stirred magnetically in airequilibrated solution, then solution samples are withdrawn to be analyzed.

Based on the established mechanism for the oxidative photodegradation of the organic dyes, the rate of the photodegradation $(\mathrm{k})$ can be defined by eq. (3):

$$
-\mathrm{d}[\text { dye }] / \mathrm{dt}=\mathrm{k}[\text { dye }]\left[\mathrm{O}_{2}\right]
$$

Since the concentration of $\mathrm{O}_{2}$ in the air-saturated solution is constant, eq. (4) can be used to define the rate process:

$$
\ln \left([\text { dye }]_{0} /[\text { dye }]_{\mathrm{t}}\right)=\mathrm{kt}
$$

straight line, the slope of which is the rate constant for oxidative degradation. In the present study, we observe a relationship between dye concentration and absorbance at $\lambda_{\text {max }}$. Therefore, the absorption values are used directly as a function of changing irradiation times (t) [19]. The experimental results arising from the dye show linear relationships between $\ln A_{t}$ an irradiation time, which indicate that the photodegradation of dyes follows first order kinetics.

2.4. Total organic carbon analysis. The total organic carbon is measured on total organic carbon analyzer Ionics Model 1555B.

2.5. Cyclic voltammetry. A three-electrode configuration consisting of different working electrodes, a reference electrode $(\mathrm{Ag} / \mathrm{AgCl}, 3 \mathrm{M} \mathrm{KCl})$ and a counter electrode (Pt wire) is used throughout the electrochemical experiments. A Pt disc electrode in Teflon housing is applied for cyclic voltametry measurements. The electrode surface is washed in distilled water and alcohol. The solutions of dyes are composed of $0.1 \mathrm{M}$ of tetrammonium chloride as an electrolyte, $0.13 \mathrm{M}$ of colloidal $\mathrm{TiO}_{2}$ and about $10^{-4} \mathrm{M}$ of Alizarin $\mathrm{R}$ and Alizarin 2G, while the concentration of other dyes is $10^{-3} \mathrm{M}$. They were deoxygenated using He gas at least 5 minutes before the experiment.

2.6. Dye-sensitized photochemical solar cells. Images for the surfaces of the conducting glass, deposited layers of $\mathrm{TiO}_{2}$ nanoparticles, and the stained $\mathrm{TiO}_{2}$ nanoparticles layers had been taken using an optical microscope OLYMPUS model CH30 from OLYMPUS Optical CO., LTD, Japan with the aid of OLYMPUS DP10 digital camera. The cell is illuminated by a 1000-W LX 700 GKF halogen lamp, Germany, equipped with UV blocking filter, an acrylic polymer filter was put in front of the lamp to block excessive IR radiation. The light source is calibrated by using digital Luxmeter, LX-102, Lurton, Taiwan, and it is found to be $45 \mathrm{~mW} / \mathrm{cm}^{2}$. The current obtained during the cell illumination is recorded with KEITHLEY 485 auto-ranging picometer, USA.

The open circuit voltage $\left(\mathrm{V}_{\mathrm{oc}}\right)$ and the short circuit current $\left(\mathrm{I}_{\mathrm{sc}}\right)$ are obtained from the $\mathrm{x}$ and $\mathrm{y}$ intercepts from the I-V curves. The maximum products of current and voltage (obtained near the knee of the curve) is divided by the incoming light power $\left(45 \mathrm{~mW} / \mathrm{cm}^{2}\right)$ to obtain the conversion efficiency of sunlight to electrical energy (see eq. (5)) [14].

$$
\begin{aligned}
& \text { \%Eff }=\frac{\text { maximum output power }}{\text { input power }} \\
& =\frac{\mathrm{I}_{\mathrm{m}} \mathrm{V}_{\mathrm{m}}}{\text { incident light intensity } \times \text { area of the active layer }} \\
& \quad \times 100
\end{aligned}
$$


Where:

$\mathrm{I}_{\mathrm{m}}=$ maximum current output (obtained near the knee of the curve),

$\mathrm{V}_{\mathrm{m}}=$ maximum voltage output (obtained near the knee of the curve).

\section{RESULTS AND DISCUSSION}

3.1. Adsorption of dyes on $\mathrm{TiO}_{2}$ surface. A preliminary study on the adsorption of several aqueous solutions of aromatic dyes containing carboxylic and hydroxyl groups on the surface of suspended fine powder of $\mathrm{TiO}_{2}$ (Degussa P25) is attempted by recording the absorption spectra of the aqueous solutions of dyes before and after the addition of $\mathrm{TiO}_{2}$.

Efficient adsorption on $\mathrm{TiO}_{2}$ particles is noticed in case of six dyes, namely; rhodamine 101 (RH), 5(6)Carboxyfluorescein (CFL), Fluorescein (FL), Alizarin yellow R (AR), Alizarin yellow 2G (AG), and Carboxyarsenazo (ASIII).<smiles>O=C([O-])C1=C(c2ccccc2C(=O)[O-])C2=C3CCCN4CCCC(=C1c1cc5c6c(c1O2)CCCN6CCC5)C34</smiles>
(RH)<smiles>NC(=O)c1cc(N=Nc2ccc([N+](=O)[O-])cc2)ccc1O</smiles>
(AR)<smiles></smiles>
(CFL)<smiles>O=C(O)c1cc(N=Nc2cccc([N+](=O)[O-])c2)ccc1O</smiles>

(AG)<smiles>O=C(O)c1ccccc1N=Nc1c(S(=O)(=O)O)cc2cc(O)c(/N=N/c3ccccc3C(=O)O)c(O)c2c1O</smiles>

(AS III)

Accordingly, these dyes have been chosen for further studies. Very low $\left(1-5 \times 10^{-6} \mathrm{M}\right)$, dye concentrations have been used to eliminate the probability of aggregation [18].

3.2. pH-effect. Since the isoelectric point of the $\mathrm{TiO}_{2}$ colloid is pH 6.8, the surface of the nanoparticles carries positive charges at $\mathrm{pH}<6.8$ and negative charges at $\mathrm{pH}>6.8$ [20]. Optimum conditions for the chemisorption can be expected for strong electrostatic attraction between dye and surface, implying that one must find conditions where the $\mathrm{TiO}_{2}$ surface is positively charged and the dye is negatively charged. This is accomplished by choosing the aqueous medium where the $\mathrm{pH}$ after addition of $\mathrm{TiO}_{2}$ becomes approximately

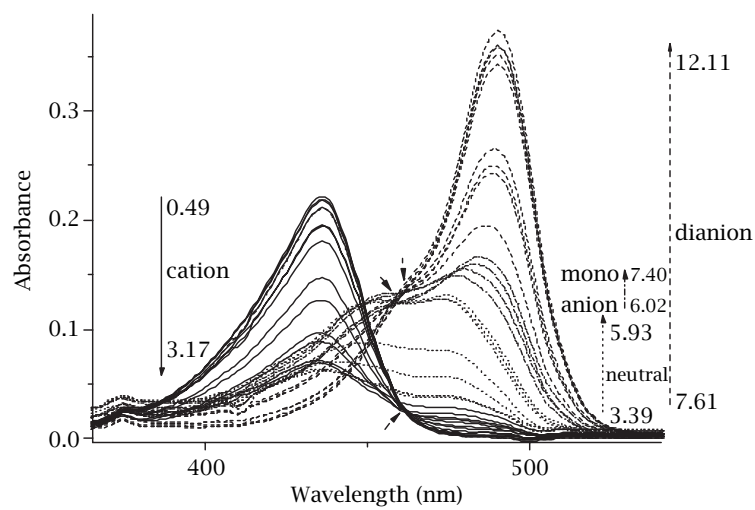

Figure 1 . The effect of the $\mathrm{pH}$ of the medium on the absorption spectrum of $4 \times 10^{-6} \mathrm{M} F L$. The $p H$ values have been adjusted using traces of $\mathrm{NaOH}$ solution or $\mathrm{HClO}_{4}$ solution (4 sets have been realized).

Table 1. The $\mathrm{pK}_{\mathrm{a}}$ values of the different dyes.

\begin{tabular}{lccccc}
\hline Dye & $\mathrm{pK}_{\mathrm{a} 1}$ & $\mathrm{pK}_{\mathrm{a} 2}$ & $\mathrm{pK}_{\mathrm{a} 3}$ & $\mathrm{pK}_{\mathrm{a} 4}$ & $\mathrm{pK}_{\mathrm{a} 5}$ \\
\hline $\mathrm{RH}$ & $1.1 \pm 0.1$ & $2.7 \pm 0.2$ & $7.2 \pm 0.1$ & - & - \\
CFL & $2.1 \pm 0.3$ & $2.5 \pm 0.3$ & $4.3 \pm 0.1$ & $6.6 \pm 0.1$ & $8.5 \pm 0.6$ \\
FL & $2.0 \pm 0.4$ & $4.3 \pm 0.4$ & $6.8 \pm 0.5$ & $9.0 \pm 0.7$ & - \\
AR & $1.0 \pm 0.8$ & $2.7 \pm 0.4$ & $10.8 \pm 0.4$ & - & - \\
AG & $1.2 \pm 0.2$ & $2.3 \pm 0.3$ & $10.9 \pm 0.1$ & - & - \\
AS III & $8.9 \pm 0.3$ & $9.7 \pm 0.4$ & $11.7 \pm 0.4$ & - & - \\
\hline
\end{tabular}

6.5 and the dyes become negatively charged-and thus the carboxylic groups are deprotonated. To have a closer look at the different ionic and neutral forms of the dyes we have determined the $\mathrm{pK}_{\mathrm{a}}$ 's of the dyes spectrophotometrically. Multi $\mathrm{pK}_{\mathrm{a}}$ values is obtained corresponding to the protonation/deprotonation of the function groups as previously reported for some candidates of these classes of dyes [21]. For example, Figure 1 shows the effect of the $\mathrm{pH}$ of the medium on the absorption spectrum of FL. Table 1 summarizes the values of the $\mathrm{pK}_{\mathrm{a}}$ 's of the different dyes.

3.3. Charge transfer complexes (the formation of surface complexes via adsorption). Figure 2 shows the effect of increasing $\mathrm{TiO}_{2}$ concentration on the absorption spectrum of CFL. The pH of the above experimental solution is kept constant at 5.5. The increase of absorbance and appearance of new absorption band at longer wavelength indicates a strong electronic coupling and a charge transfer type of interaction between the dye molecules and $\mathrm{TiO}_{2}$ nanoparticles. Similar behavior has been noticed in case of other dyes under investigation.

The considerable amount of shift in the absorption spectrum of the dye molecules upon binding to the nanoparticles can be explained in terms of complex formation as well as charge transfer transitions via 


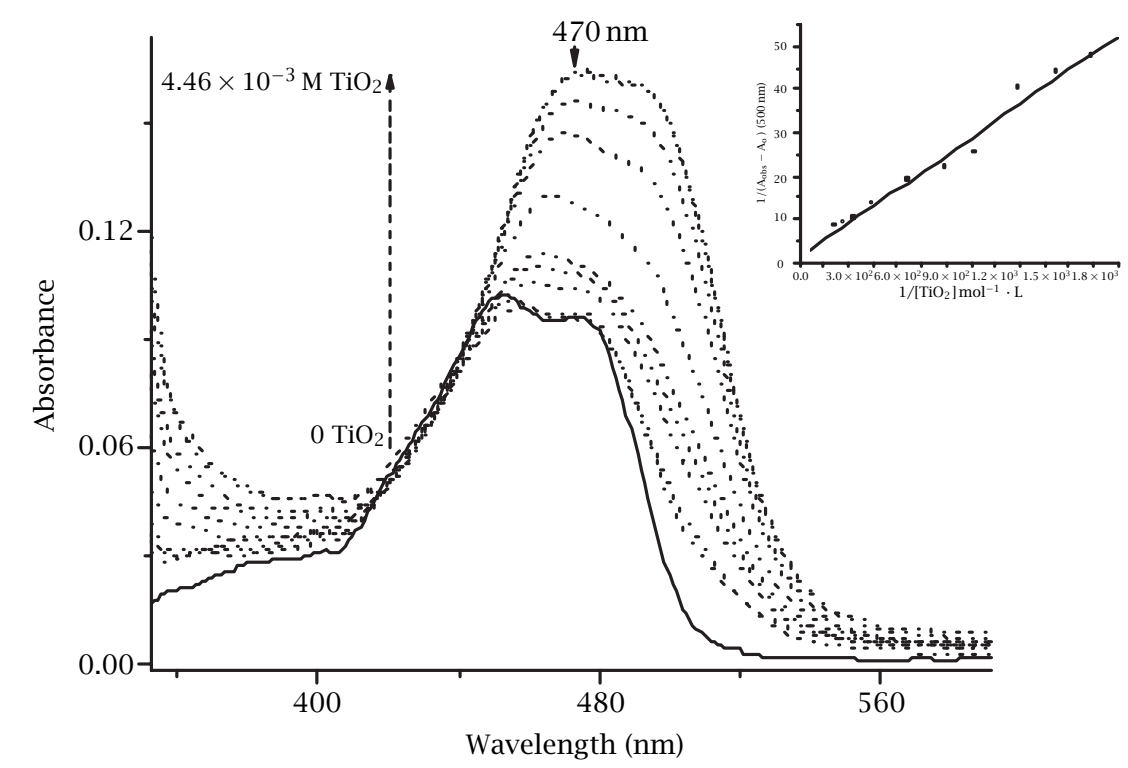

Figure 2. The effect of addition of $\mathrm{TiO}_{2}$ colloidal solution on the absorption spectrum of $4 \times 10^{-6} \mathrm{M}$ CFL aqueous solution.

Table 2. The estimated apparent association constants $\mathrm{K}_{\mathrm{app}}$ of the dye-surface complexes using the Benesi-Hildbrand equation (2).

\begin{tabular}{lc}
\hline Dye & $\log \left(\mathrm{K}_{\mathrm{app}}\right), \mathrm{M}^{-1}$ \\
\hline RH & 1.167 \\
CFL & 1.613 \\
FL & 1.973 \\
AR & 3.156 \\
AG & 3.369 \\
AS III & 4.251 \\
\hline
\end{tabular}

electron transfer between $\mathrm{TiO}_{2}$ and the dye molecule that results in the considerable red shift due to relaxation of the energy levels of the dye. This is in agreement with similar results previously reported [22]. The Benesi-Hilderband plot for the dye- $-\mathrm{TiO}_{2}$ nanoparticle system is shown in the insertion. The association constants $\left(\mathrm{K}_{\mathrm{app}}\right)$ of the complexes are summarized in Table 2.

Figure 3 shows the fluorescence spectra of FL dye molecules in water, and at different concentrations of $\mathrm{TiO}_{2}$ colloidal solution. It has been observed that in the presence of $\mathrm{TiO}_{2}$ nanoparticles, the emission intensity of the dye molecules decreases dramatically. This is attributed to the electron injection from the excited state of the dye molecules to the conduction band of the nanoparticles.

\subsection{Investigation of the effect of the dyes on the} reduction potential of $\mathrm{TiO}_{2}$. More evidence of the electron injection from the dye molecule into $\mathrm{TiO}_{2}$ due to surface complex formation has been obtained from the cyclic voltammogram of $\mathrm{TiO}_{2}$ in aqueous medium,

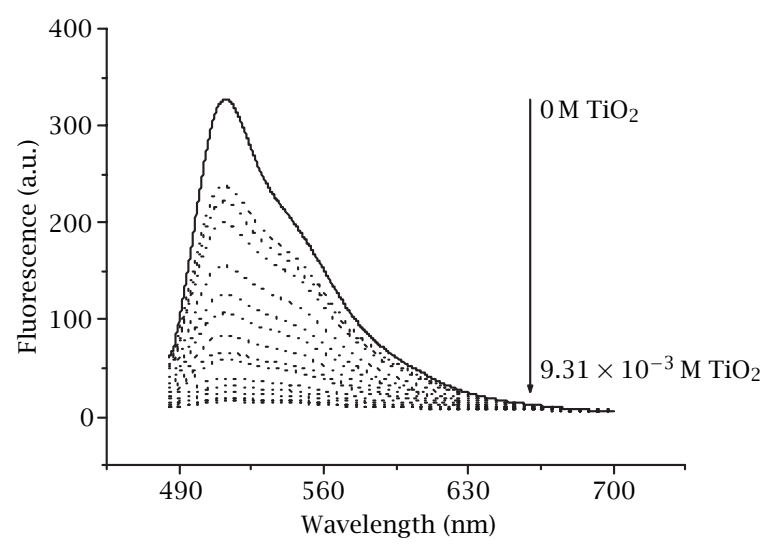

Figure 3. The effect of addition of colloidal $\mathrm{TiO}_{2}$ aqueous solution on the fluorescence spectrum of $4 \times 10^{-6} \mathrm{M}$ FL aqueous solution. $\lambda_{\mathrm{ex}}=475 \mathrm{~nm}$.

in absence and presence of dye molecules. Figure 4 shows the effect of the addition of AS III on the CV of $\mathrm{TiO}_{2}$. The negative shifts in the reduction potentials of $\mathrm{TiO}_{2}$ upon the addition of dye molecules confirm the formation of surface complexes via a chemisorption process. The difficulty of $\mathrm{TiO}_{2}$ to be reduced in presence of dye molecules is consistent with the values of the apparent association constants $\mathrm{K}_{\mathrm{app}}$ estimated from Benesi-Hilderband equation. As the $K_{a p p}$ increases the reduction potential of $\mathrm{TiO}_{2}$ is more negatively shifted. In other words, as bonding with the dye becomes stronger with a consequent flow of electrons to $\mathrm{TiO}_{2}$, the ability of $\mathrm{TiO}_{2}$ to gain more electrons from the Pt working electrode becomes harder. The correlation between the reduction potentials of $\mathrm{TiO}_{2}$ and the apparent association constant $\mathrm{K}_{\mathrm{app}}$ is shown in Figure 5. 


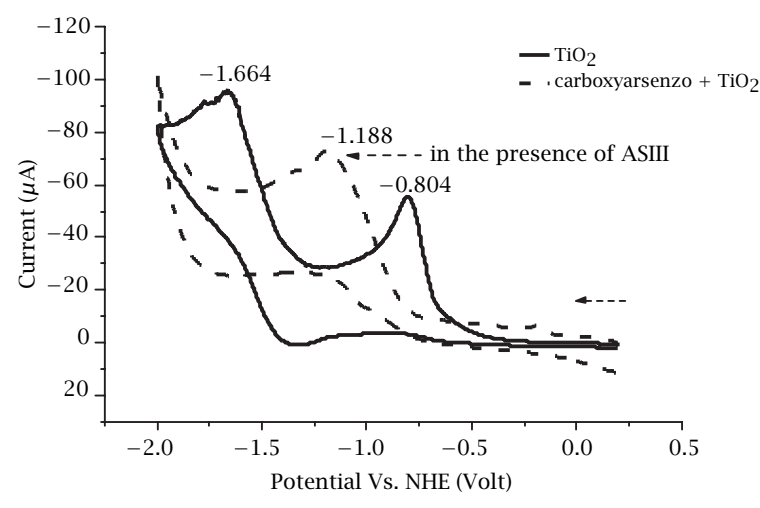

Figure 4. The effect of ASIII solution on the CV of aqueous colloidal solution of $\mathrm{TiO}_{2}$.

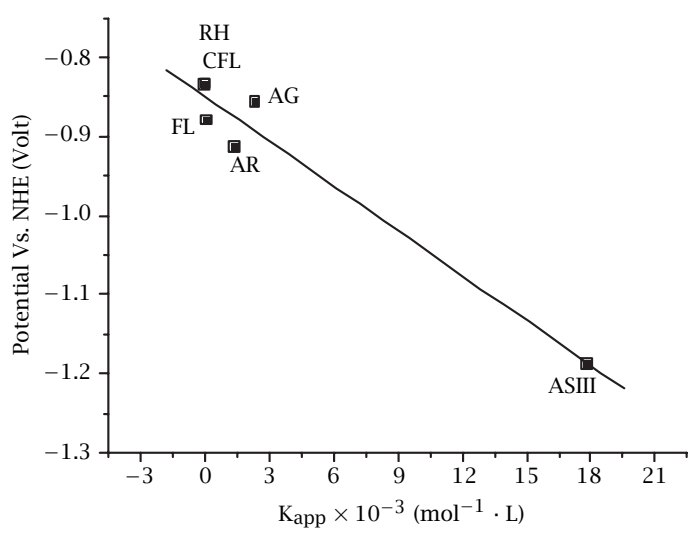

Figure 5. Correlation between apparent association constants $\mathrm{K}_{\mathrm{app}}$ and the reduction potentials of $\mathrm{TiO}_{2}$.

Table 3. The effect of dye molecules on the reduction potential of $\mathrm{TiO}_{2}$ solution.

\begin{tabular}{cc}
\hline Dye & Reduction potential of $\mathrm{TiO}_{2}$ \\
\hline Aqueous solution & -0.804 \\
RH & -0.836 \\
CFL & -0.834 \\
FL & -0.880 \\
AR & -0.914 \\
AG & -0.856 \\
AS III & -1.188 \\
\hline
\end{tabular}

It appears clearly that RH, which has the lowest $\mathrm{K}_{\mathrm{app}}$ shows the smallest negative shift; in contrast, AS III shows the largest shift. Table 3 shows the numerical data of reduction potential of $\mathrm{TiO}_{2}$ solution and the effect of the dyes.

3.5. Studies the effect of $U V$-visible irradiation on the dyes and the surface complexes. So far the experimental results confirm charge migration process

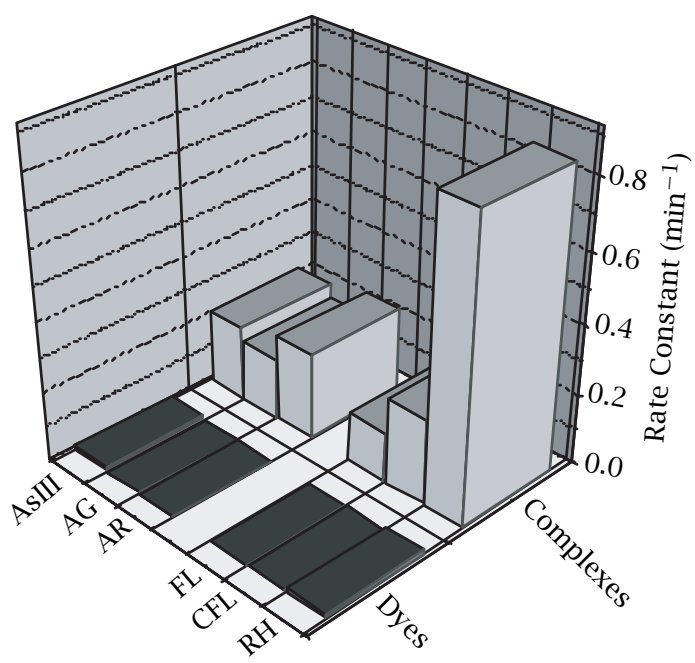

Figure 6. The initial rate constants of the degradation of different dyes in aqueous medium (in absence and presence of $\mathrm{TiO}_{2}$ ).

from the dye molecules into $\mathrm{TiO}_{2}$. The problem to be tackled now is the high possibility of photocatalytic oxidative degradation of the dye molecules by highly reactive oxidative species (such as $\mathrm{O}_{2}^{-{ }^{-}}$) that may be generated upon illumination of the solution containing $\mathrm{TiO}_{2}$ [23].

A high degree of photostability of 5(6)-carboxyfluorescein, AR and AG-in absence of $\mathrm{TiO}_{2^{-}}$is noticed and no change in their absorption spectra was observed after 90 minutes of irradiation. On the other hand, RH, FL and AS III show some degree of light response and are thus photolabile. Moreover, extra photostability of CFL over FL is attributed to the presence of extra carboxylic group which stabilizes the molecular system by conjugation.

Table 4 summarizes the initial rate constants and the half-life times of the photodegradation reaction in the absence and presence of $4 \mathrm{mM} \mathrm{TiO}_{2}$. It is observed that, in the presence of $\mathrm{TiO}_{2} \ln \mathrm{A}_{\mathrm{t}}$ decreased linearly with the time of irradiation reflecting first-order kinetics with excellent correlation coefficients varied in the range of 0.999. A summary of the kinetics of photodegradation is shown in Figure 6 for comparison.

The results of TOC measurements show that only partial degradation is achieved upon UV-VIS irradiation for more than 6 hours (see Figure 7).

Interestingly, the presence of $\mathrm{KI} / \mathrm{I}_{2}$ electrolyte results in a dramatic increase in the photostability of dye- $\mathrm{TiO}_{2}$ complex molecules as has been seen from the examination of the absorption spectrum of the complexes for over hours of light illumination. This can be attributed to the fast regeneration of the oxidized dye in the presence of the electrolyte according to the 
Table 4. The initial rate constants and half-life time values of the photodegaradation of different dyes in aqueous medium (in absence and presence of $\mathrm{TiO}_{2}$ ).

\begin{tabular}{lcccc}
\hline Dye & \multicolumn{2}{c}{ In presence of $\mathrm{TiO}_{2}$} & \multicolumn{2}{c}{ In absence of $\mathrm{TiO}_{2}$} \\
$\begin{array}{c}\text { Initial rate constant } \\
\left(\mathrm{min}^{-1}\right)\end{array}$ & $\begin{array}{c}\text { Half-life time } \mathrm{t}_{0.5} \\
(\mathrm{~min})\end{array}$ & $\begin{array}{c}\text { Initial rate constant } \\
\left(\mathrm{min}^{-1}\right)\end{array}$ & $\begin{array}{c}\text { Half-life time } \mathrm{t}_{0.5} \\
(\mathrm{~min})\end{array}$ \\
\hline $\mathrm{RH}$ & 0.85 & 0.8 & 0.01 & 63.0 \\
$\mathrm{FL}$ & 0.14 & 4.9 & 0.00 & - \\
$\mathrm{CFL}$ & 0.24 & 2.8 & 0.00 & 346.6 \\
$\mathrm{AR}$ & 0.25 & 2.8 & 0.00 & - \\
$\mathrm{AG}$ & 0.18 & 3.9 & 0.00 & - \\
AS III & 0.22 & 3.2 & 0.01 & 53.3 \\
\hline
\end{tabular}

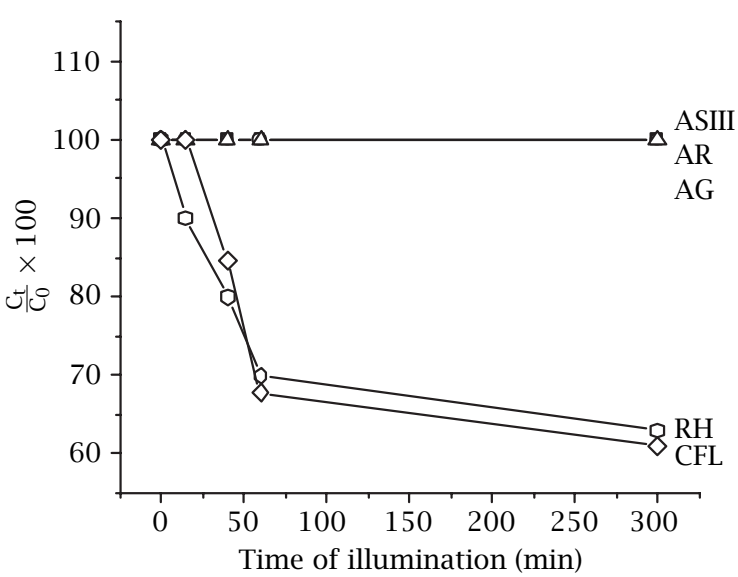

Figure 7. The amount of the remaining TOC percentage during the photodegradation reaction of different dyes- $\mathrm{TiO}_{2}$ surface complexes for 6 hrs of illumination (UV/Vis).

following mechanism:

$$
\begin{aligned}
& \left(\text { Dye }-\mathrm{TiO}_{2}\right)+\mathrm{h} v \longrightarrow\left(\text { Dye }^{*}-\mathrm{TiO}_{2}\right) \\
& \left(\text { Dye }^{*}-\mathrm{TiO}_{2}\right) \longrightarrow\left(\text { Dye }^{+}-\mathrm{TiO}_{2}\right)+\text { ejected } \mathrm{e}^{-} \\
& \left(\text {Dye }^{+}-\mathrm{TiO}_{2}\right)+\frac{3}{2} \mathrm{I}^{-} \longrightarrow\left(\text { Dye- } \mathrm{TiO}_{2}\right)+\frac{1}{2} \mathrm{I}_{3}{ }^{-}
\end{aligned}
$$

3.6. Fabrication of dye-sensitized solar cells (DSC). The results obtained prompted us to design a model of DSC. A commercially available glass plate coated with a conductive layer of antimony-doped $\mathrm{SnO}_{2}$ $(2.5 \mathrm{~cm} \times 2.5 \mathrm{~cm})$ is used as the starting material for the electrodes. Deposition of $\mathrm{TiO}_{2}$ layer on the surface of the conductive glass is carried out using colloidal $\mathrm{TiO}_{2}$ nanoparticles solution. Then staining titanium dioxide layers with the dye molecules is carried out and an optical image is shown in Figure 8.

The photocurrent action spectrum of the surfacemodified $\mathrm{TiO}_{2}$ film with 5(6)-carboxyfluorescein closely matches the absorption spectrum of the sensitizer as shown in Figure 9. Photocurrent action spectrum shows the origin of photoelectric output to be optical absorp-

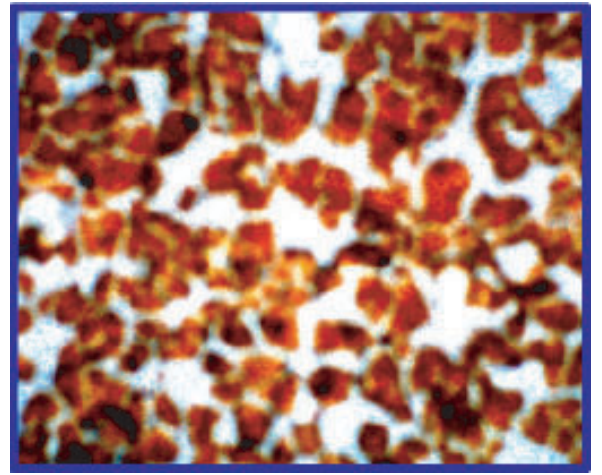

Figure 8. Optical image for stained $\mathrm{TiO}_{2}$ layer with CFL deposited on Sb-doped $\mathrm{SnO}_{2}$ conductive glass. (The magnification power, $m . p .=4 \times 8$.)

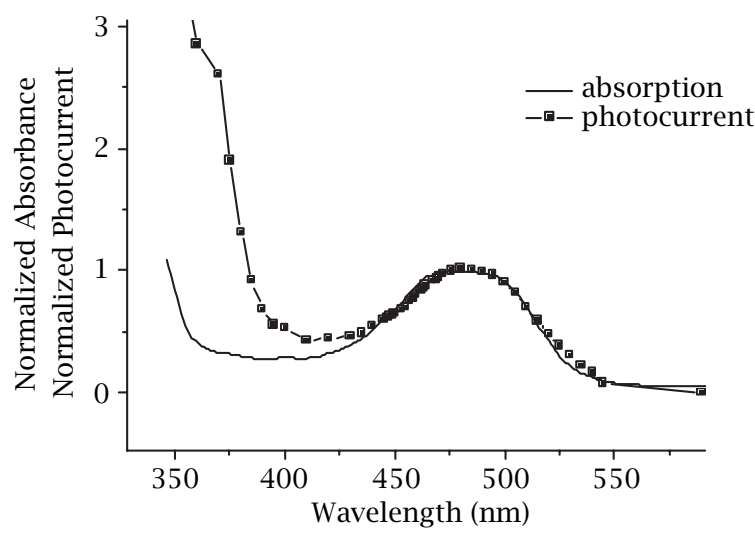

Figure 9. Photocurrent action spectrum of CFL photoelectrochemical cells (broken line), and absorption spectrum of CFL-TiO 2 surface complex in aqueous solution.

tion of the CFL dye. Similar results are obtained for other dyes.

It is thus obvious that, when the $\mathrm{TiO}_{2}$ electrode is illuminated with visible light, the sensitizer antenna molecules absorb light and inject electrons into the 


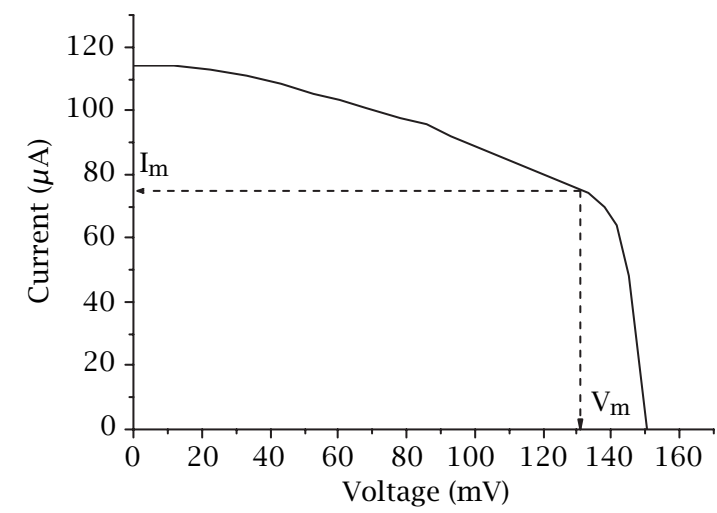

Figure 10. Current-Voltage [I-V] curve for visibleilluminated CFL-sensitized solar cells. The open circuit current and short circuit voltage are obtained from the $x$ and $y$ intercepts coordinates, respectively.

$\mathrm{TiO}_{2}$ particles. These electrons are then collected at the conducting glass surface to generate anodic photocurrent. The redox couple (e.g. $\mathrm{I}_{3}{ }^{-} / \mathrm{I}^{-}$) present as an electrolyte in the DSC quickly regenerates the neutral sensitizer dye molecules and photocurrent flows continuously as long as the cell is illuminated.

Current-Voltage characteristics [I-V curves] for the cells have been plotted (see Figure 10 for CFL as an example). The electrical output values are remarkable, considering the simple preparation procedure for this cell. CFL dye sensitized cell is the only promising system among other DSC's tested in the present study. The overall energy conversion efficiency of CFL dye sensitized cell is found to be $4.8 \%$ at $45 \mathrm{~mW} / \mathrm{cm}^{2}$. Lower photoconversion efficiencies are obtained in case of other dyes. It is noteworthy to mention that no relationship is found between the photoconversion efficiency and the association constants of dyes studied.

\section{CONCLUSIONS}

The paper reports the interaction of sensitizing dyes [xanthenes (rhodamine 101, fluorescein and 5(6)carboxyfluorescein) and selected azo dyes (alizarin yellow R, alizarin yellow $2 \mathrm{G}$ and carboxyarsenazo)] with $\mathrm{TiO}_{2}$. We have carried out a series of experiments to evaluate the performance of these dyes in dyesensitized solar cells. The interpretation of results is based on well-established concepts. No correlation is found between the photoconversion efficiencies (IPCE) of different dyes and the association constants.

\section{REFERENCES}

[1] B. O’Regan and M. Gräetzel, Nature 353 (1991), 737; B. A. Gregg, J. Phys. Chem. B 107(20) (2003), 4688; A. L. Fahrenbruch and R. H. Bube, Fundamen- tals of Solar Cells. Photovoltaic Solar Energy Conversion, Academic Press, New York, 1983; G. Yu, J. Gao, J. C. Hummelen, F. Wudl, and A. J. Heeger, Science 270 (1995); J. J. M. Halls, C. A. Walsh, N. C. Greenham, E. A. Marseglia, R. H. Friend, S. C. Moratti, and A. B. Holmes, Nature 376 (1995), 498; A. Hagfeldt and M. Gratzel, Acc. Chem. Res. 33 (2000), 269; E. Figgemeier and Anders Hagfeldt, Intern. J. Photoenergy 6 (2004), 127.

[2] J. He, J. Zhao, T. Shen, H. Hidaka, and N. Serpone, J. Phys. Chem. B 101 (1997), 9027.

[3] P. V. Kamat, Electron Transfer Processes in Nanostructured Semiconductor Thin Films, In: Nanoparticles and Nanostructured Films (J. H. Fendler, ed.), 1997, p. 207.

[4] C. Nasr, D. Liu, S. Hotchandani, and P. V. Kamat, J. Phys. Chem. 100 (1996), 11054.

[5] N. Papageorgiou, C. Barbé, and M. Gräetzel, J. Phys. Chem. B 102 (1998), 4156.

[6] G. Schlichthorl, S. Y. Huang, J. Sprague, and A. J. Frank, J. Phys. Chem. B 101 (1997), 8141.

[7] T. Hannappel, B. Burfeindt, W. Storck, and F. Willig, J. Phys. Chem. B 101 (1997), 6799.

[8] C. Nasr, S. Hotchandani, W. Y. Kim, R. H. Schmehl, and P. V. Kamat, J. Phys. Chem. B 101 (1997), 7480.

[9] N. J. Cherepy, G. P. Smestad, M. Gräetzel, and J. Z. Zhang, J. Phys. Chem. B 101 (1997), 9342.

[10] A. Zaban, S. Ferrere, and B. A. Gregg, J. Phys. Chem. B 102 (1998), 452.

[11] J. He, H. Lindstrom, A. Hagfeldt, and S. Lindquist, J. Phys. Chem. B 103 (1999), 8940.

[12] K. Schwarzburg and F. Willig, J. Phys. Chem. B 103 (1999), 5743.

[13] T. Trupke, P. Wurfel, I. Uhlendorf, and I. Lauermann, J. Phys. Chem. B 103 (1999), 1905.

[14] G. P. Smestad and M. Gratzel, Journal of Chemical Education 75 (1998), 752 and references therein.

[15] M. Hilgendorff and V. Sundstrom, J. Phys. Chem. B 102 (1998), 10505.

[16] G. Benko, M. Hilgendorff, A. P. Yartsev, and V. Sundstrom, J. Phys. Chem. B 105 (2001), 967.

[17] S. Gorog, Ultraviolet-Visible Spectrophotometry in Pharmaceutical Analysis, CRC press, 1995, p. 88.

[18] G. Ramakrishna and H. N. Ghosh, J. Phys. Chem. B 105 (2001), 7000 and references therein.

[19] S. Yang, H. Tian, H. Xiao, X. Shang, X. Gong, S. Yao, and K. Chen, Dyes and pigments 94 (2001), 93.

[20] M. M. Halmann, Photodegradation of Water Pollutants, CRC Press, Boca Raton, New York, 1996.

[21] M. Jose, L. Ballesteros, E. Talavera, and J. J. Yguerabide, J. Phys. Chem. A 105 (2001), 6320; X. Zhai and S. Efrima, Langmuir 13 (1997), 420.

[22] G. Ramakrishna and H. N. Ghosh, J. Phys. Chem. B 105 (2001), 7000.

[23] S. Yang, H. Tian, H. Xiao, X. Shang, X. Gong, S. Yao, and K. Chen, Dyes and Pigments 94 (2001), 93. 


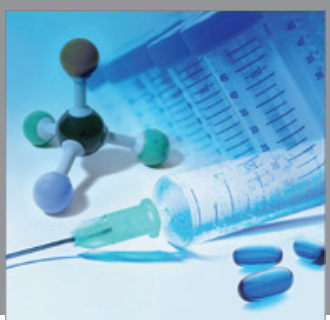

International Journal of

Medicinal Chemistry

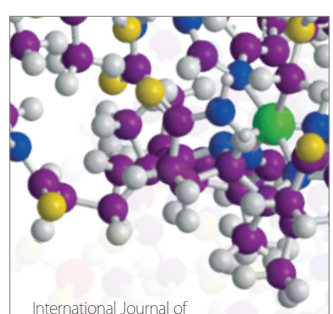

Carbohydrate Chemistry

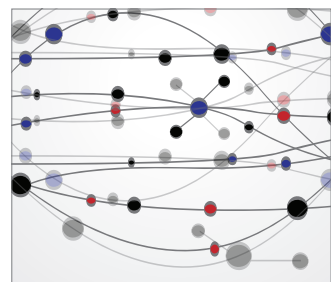

The Scientific World Journal
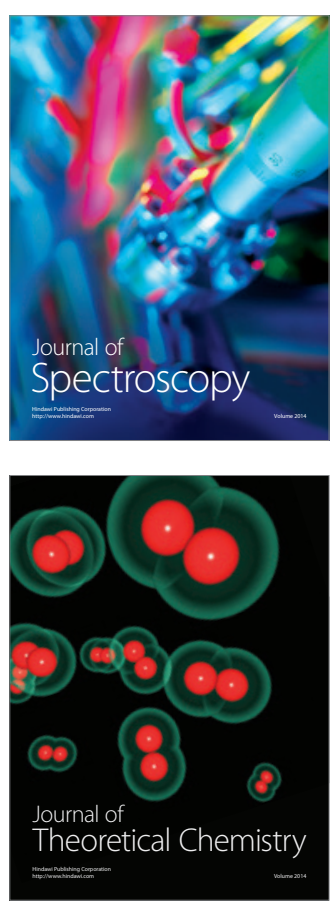
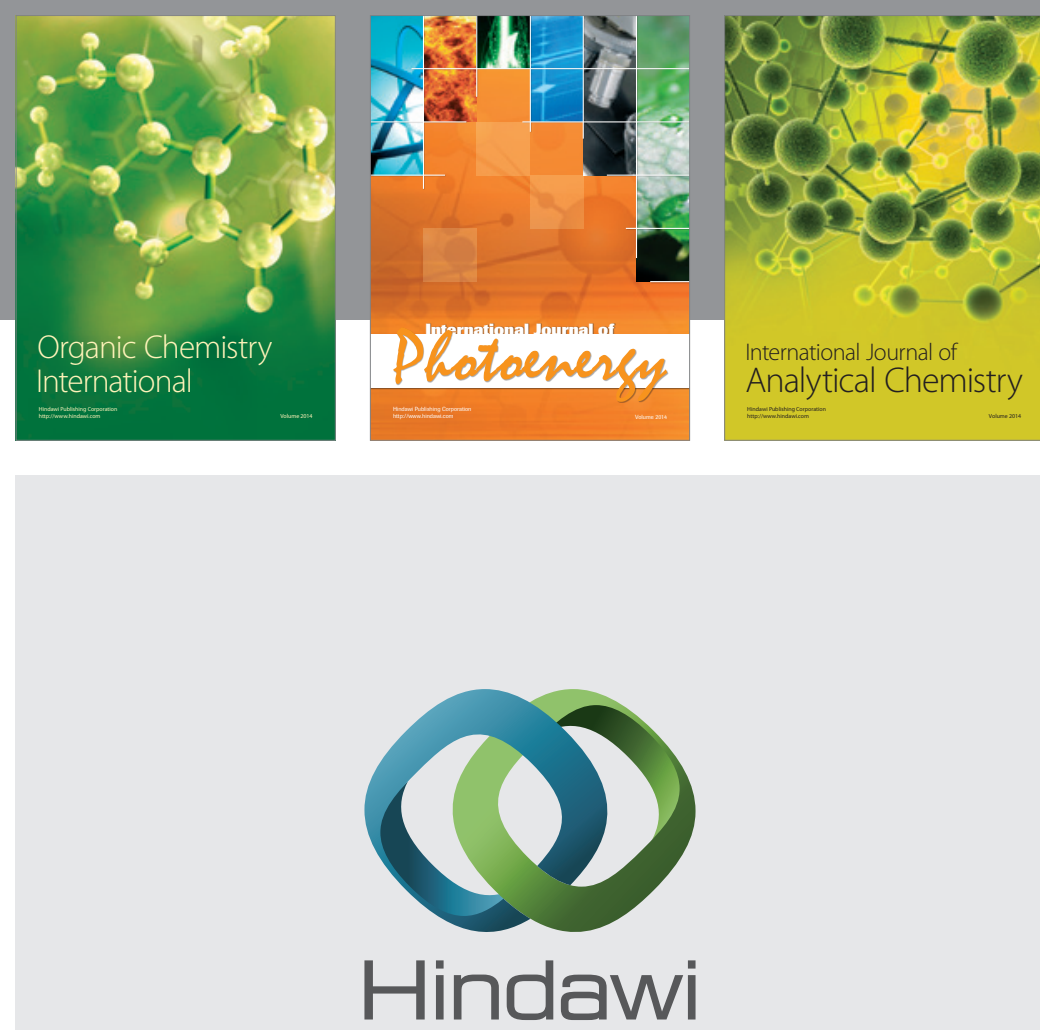

Submit your manuscripts at

http://www.hindawi.com
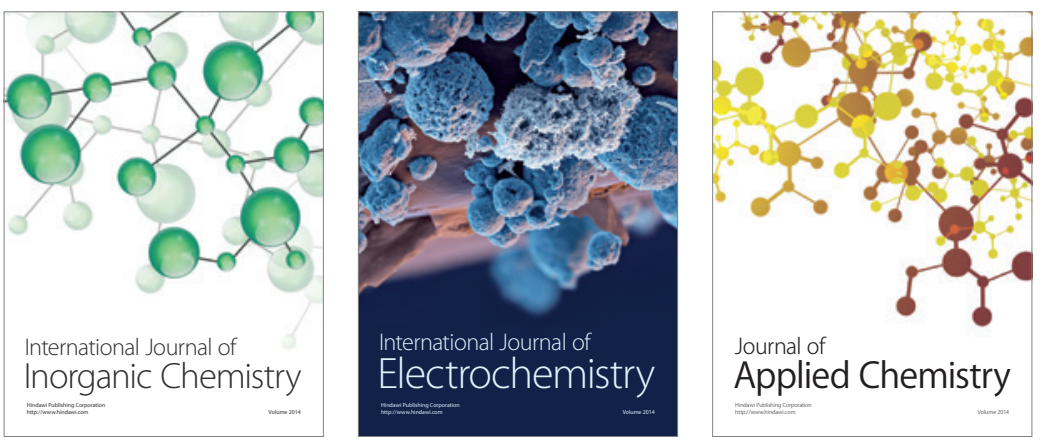

Journal of

Applied Chemistry
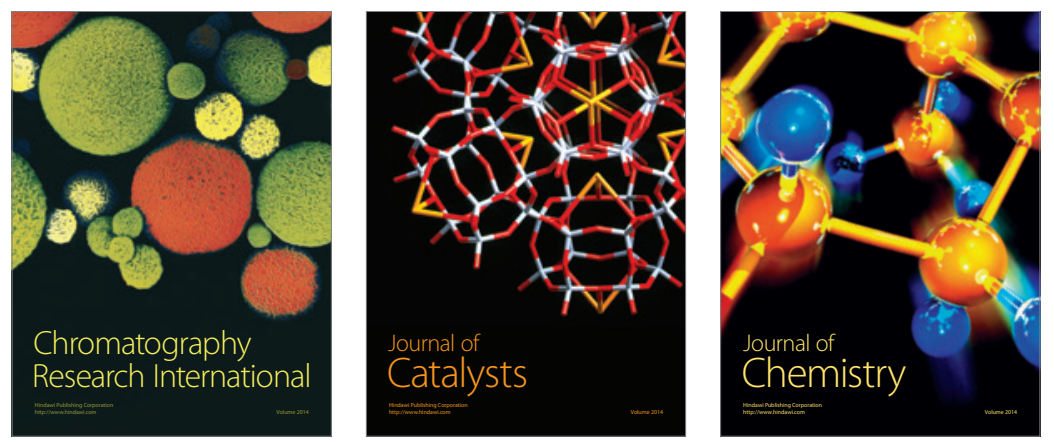
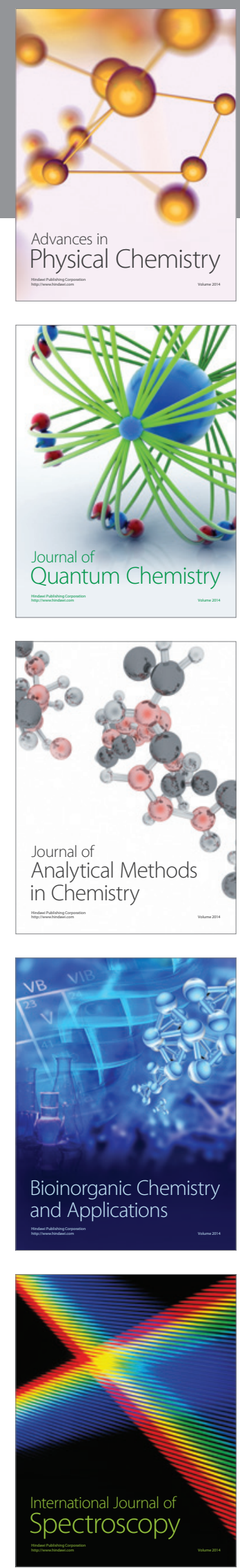